\title{
Commitment to Differentiation Induced by Retinoic Acid in P19 Embryonal Carcinoma Cells Is Cell Cycle Dependent
}

\author{
C. L. Mummery, ${ }^{1}$ C. E. van den Brink, and S. W. DE LaAt \\ Hubrecht Laboratorium, Uppsalalaan 8, 3584 CT Utrecht, The Netherlands \\ Received July 15, 1986; accepted in revised form November 13, 1986
}

\begin{abstract}
The rate at which $\mathrm{P} 19$ embryonal carcinoma cells in monolayer culture become anchorage dependent during differentiation induced by retinoic acid (RA) was investigated. In both nonsynchronized cultures and cultures synchronized by mitotic selection, the ability to grow in semisolid medium, characteristic of the malignant stem cell, decreased after a lag period of about $12 \mathrm{hr}$ in the continuous presence of RA, prior to an increase in cell generation time. However, striking differences between synchronized and nonsynchronized cultures were observed in their commitment to differentiation following RA removal. After only $2 \mathrm{hr}$ of exposure to RA, synchronized cells continued a program of differentiation in which they became anchorage dependent, while at least $24 \mathrm{hr}$ of exposure was required for exponentially growing cells to become similarly committed. Induction of anchorage dependence by RA was also strikingly cell cycle dependent; 2 or $4 \mathrm{hr}$ of exposure of synchronized cells to $\mathrm{RA}$ in $\mathrm{G}_{1}$ phase, when the intrinsic capacity for soft agar growth is low, was sufficient to commit cells to anchorage dependence, but a similar exposure in $S$ phase was not. Together, these results suggested that interactions between cells in different cell cycle phases in asynchronous cultures influenced commitment since exposure to $\mathrm{RA}$ for more than one cycle $(13 \mathrm{hr})$ was required for all cells to become anchorage dependent. Increased plasminogen activator secretion and epidermal growth factor binding, markers of certain differentiated cell types, increased only 3 and 5 days after RA addition, respectively, and were not induced by pulsed exposure to RA of less than $24 \mathrm{hr}$, even in synchronized cells. (C) 1987 Academic Press, Inc.
\end{abstract}

\section{INTRODUCTION}

Embryonal carcinoma (EC) cells are the undifferentiated stem cells derived from mouse teratocarcinomas. They are frequently used as a model system to study events involved in early development because of the many properties they have in common with pluripotent embryonic cells (Graham, 1977; Martin, 1980). Most EC cells can be induced to differentiate when cultured in the presence of retinoic acid (RA). The cell types formed following RA exposure depend on the particular EC cell line, on whether the EC cells are cultured in cell aggregates or on solid surfaces, and on the drug concentration (Strickland and Mahdavi, 1978; Hogan et al., 1981; JonesVilleneuve et al., 1982; Edwards and McBurney, 1983). Differentiation is marked by dramatic changes in cell phenotype, including loss of the capacity for anchorageindependent growth 24-48 hr after induction (Jetten et al., 1979; Strickland et al., 1980). However, the precise temporal rclationship between these changes, the extent to which they are reversible, and whether altered proliferation rate is a cause or consequence of differentiation is at present unclear (reviewed in Sherman, 1986).

Several approaches have been used to investigate reversibility and commitment in differentiating EC cells. Ogiso et al, (1982) studied the loss of peanut agglutinin

\footnotetext{
${ }^{1}$ To whom reprint requests should be addressed.
}

(PNA) binding induced by RA in 311 EC cells; although 4 days of exposure induced an irreversible loss, cells exposed for only 2 days reacquired PNA binding within 5 $\mathrm{hr}$ in RA-free medium. Rayner and Graham (1982) have shown that $24 \mathrm{hr}$ of exposure of cloned PC13 EC cells was sufficient to induce the same pattern of changes in growth kinetics as continuous exposure to the inducer; i.e., the cells grew unimpeded for a further $24 \mathrm{hr}$ after RA removal before cell division ceased. Recently, we have analyzed changes in cell cycle kinetics induced by RA in more detail using mitotically synchronized PC13 EC cells and have related these changes to those in cell morphology (Mummery et al., 1984). PC13 EC cells have a restricted differentiation potential but following addition of RA to monolayer cultures an apparently homogeneous cell type PC13 END is formed (Rees et al., 1979). While the flattened phenotype, typical of PC13 END, was acquired in the second cell cycle after induction, cell cycle times only increased from the third cycle. Together these data indicate that (i) a limited exposure to RA is sufficient to induce commitment for differentiation, (ii) the appearance of the differentiated phenotype is related to the cell cycle after induction, and (iii) certain differentiated characteristics are elicited prior to the point at which cell cycle kinetics for treated and untreated cells diverge.

In the present study we have again used mitotically synchronized EC cells but now to characterize in detail 
the differentiation of pluripotent EC cell line, P19 (McBurney and Rogers, 1982; McBurney et al., 1982; Jones-Villeneuve et al., 1982). In particular, we wished to identify early phenotypic alterations associated with commitment to different cell lineages and to establish the relationship with the loss of tumorigenic potential. P19 EC cells form neuroectodermal derivatives or striated muscle when aggregated in the presence of RA and DMSO, respectively, and mesodermal or endodermal derivatives when treated in monolayer with RA. The kinetics of appearance of a number of differentiated characteristics during RA-induced differentiation were compared, and time points at which RA removal was no longer able to affect these kinetics were established. The results demonstrated that only very short exposures to RA were required to commit tumorigenic EC cells to loss of their capacity for growth in semisolid media, while significantly longer exposures were required to commit cells to the expression of certain differentiation markers, namely, plasminogen activator (PA) production and epidermal growth factor (EGF) binding. Furthermore, a striking difference between the response of exponentially growing cultures and synchronized cultures to RA in terms of commitment suggested that sensitivity to RA may be cell cycle dependent. This was confirmed by exposing cells to short (2- or 4-hr) pulses of RA during different cell cycle phases; a 2 -hr pulse in $\mathrm{G}_{1}$ phase was sufficient to abolish growth in soft agar $75 \mathrm{hr}$ later whereas a similar pulse in S phase only marginally reduced growth compared with untreated control cells. The implications of these findings are discussed.

\section{MATERIALS AND METHODS}

\section{Cell Culture and Differentiation}

P19 EC cells were cultured as described previously (Mummery et al., 1985) on gelatinized flasks in a 1:1 mixture of Dulbecco's minimum essential medium (DMEM) and Ham's F12 medium (DF) containing $7.5 \%$ fetal calf serum (FCS; Flow Laboratories) and buffered with $\mathrm{NaHCO}_{3}(44 \mathrm{mM})$ in a $7.5 \% \mathrm{CO}_{2}$ atmosphere. Cells were subcultured in $0.125 \%(\mathrm{w} / \mathrm{v})$ trypsin, $50 \mathrm{~m} M$ EDTA in $\mathrm{Ca}^{2+}, \mathrm{Mg}^{2+}$-free phosphate-buffered saline. To induce differentiation, EC cells were plated at a density of 1 $\times 10^{4} / \mathrm{cm}^{2}$ in DF $+7.5 \%$ FCS and RA was added $24 \mathrm{hr}$ later to a concentration of $1 \times 10^{-6} \mathrm{M}$ from a $10^{-2} \mathrm{M}$ stock solution, dissolved in DMSO, and stored at $-70^{\circ} \mathrm{C}$. The duration of RA exposure was varied as required and is indicated in the results of individual experiments.

\section{Cell Synchronization}

For synchronization by mitotic shake off, $12 \times 10^{6} \mathrm{EC}$ cells were inoculated in a $150-\mathrm{cm}^{2}$ gelatinized tissue cul- ture flask in growth medium and incubated for $24 \mathrm{hr}$ at $37^{\circ} \mathrm{C}$. This medium was then replaced by $5 \mathrm{ml}$ of growth medium, buffered with Hepes $(15 \mathrm{mM})$ and $\mathrm{NaHCO}_{3}(15$ $\mathrm{m} M$ ), and pregassed in a $2 \% \mathrm{CO}_{2}$ atmosphere to $\mathrm{pH}$ 7.4. The flask was then shaken manually, yielding 0.3-0.5 $\times 10^{6}$ mitotic cells in suspension as large single cells. These cells were replated at a density of $2 \times 10^{4} / \mathrm{cm}^{2}$; within 20 min, cells attached and more than $95 \%$ divided into two, indicating the degree of synchrony. The appearance of cell pairs was designated as time zero. RA was then added for the period required, as indicated under Results. Duration of cell cycle phases was determined from $\left[{ }^{3} \mathrm{H}\right]$ thymidine incorporation into DNA and film analysis, as previously described for PC13 EC cells (Mummery et al., 1984).

\section{Soft Agar Growth}

The percentage of cells able to form colonies in soft agar at particular times during the cell cycle or after induction of differentiation was determined by plating $1 \times 10^{4}$ cells in DF $+20 \%$ FCS with $0.375 \%$ agar onto a base layer of $0.5 \%$ agar in $60-\mathrm{mm}$ petri dishes (Costar), as described by Todaro et al. (1981). Colonies larger than 8 cells were scored after $10-12$ days by counting 20 random fields corresponding to $2.3 \%$ of the total dish area. Data are expressed as the percentage of cells plated able to form colonies.

\section{Plasminogen Activator (PA) Production}

Synchronized cells were plated at a density of $2 \times 10^{4}$ cells $/ \mathrm{cm}^{2}$ in $3.5-\mathrm{cm}$ dishes in the presence of RA for the period indicated or in its absence. At $t=50 \mathrm{hr}, 800 \mu \mathrm{l}$ of growth medium was added to each dish and incubated for a further $20 \mathrm{hr}$. At $t=70 \mathrm{hr}$, cells were counted and the PA present in $50 \mu \mathrm{l}$ of conditioned medium was determined as described previously (Mummery et al., 1985). For exponentially growing cultures, cells were plated for $12 \mathrm{hr}$ before RA addition at $t=0$. Medium $(800 \mu \mathrm{l})$ was conditioned for either 8 or $16 \mathrm{hr}$ at various times thereafter and the PA present in 50- $\mu$ l samples was determined as described above. Data were expressed as equivalent units of urokinase activity per $10^{8}$ cells per hour or per milligram of cell protein per hour, as indicated. Cell protein was determined according to the method of Lowry et al. (1951).

\section{${ }^{125}$ I-EGF Binding}

Cells were plated in $3.5-\mathrm{cm}$-diameter gelatinized petri dishes in the presence or absence of RA at a density such that each contained $0.5-1 \times 10^{6}$ cells at the time EGF binding was determined. The binding medium con- 
sisted of $1 \mathrm{ml}$ of DMEM, Hepes ( $25 \mathrm{mM}$ ) with $0.1 \%$ (w/ v) bovine serum albumin containing $1.67 \times 10^{-10} \mathrm{M}^{125} \mathrm{I}$ EGF (Amersham $250.000 \mathrm{cpm}$ ), and varying amounts of unlabeled EGF ( 0 to $2 \times 10^{8} M$ ), as previously described (Mummery et al., 1985). After labeling, cells were incubated for $2 \mathrm{hr}$ at room temperature $\left(\mathrm{ca} .20^{\circ} \mathrm{C}\right.$ ) aspirated, and the dishes were washed five times with ice-cold PBS. Cells were solubilized in $0.5 \mathrm{M} \mathrm{NaOH}$ and radioactivity was counted in a gamma counter. Nonspecific binding, determined by measuring the bound counts in the presence of excess unlabeled EGF (200-fold over ${ }^{125}$ I-EGF), was less than $10 \%$ of the specifically bound counts.

\section{Immunofluorescence}

Cells grown on gelatinized plastic coverslips in the presence or absence of $\mathrm{R} \Lambda$ as required were fixed in ethanol at $-20^{\circ} \mathrm{C}$ for $10 \mathrm{~min}$, washed in PBS, and incubated for $30 \mathrm{~min}$ at $37^{\circ} \mathrm{C}$ with antibody followed by the appropriate FITC-labeled conjugate. The antibodies used were monoclonal anti-SSEA-1 diluted 1:250 (Solter and Knowles, 1978), rabbit anti-mouse laminin diluted 1:20 (BRL, Cambridgc, UK), and TROMA-1 diluted 1:10 (Kemler et al., 1981) which recognizes a 55K protein of intermediate filaments on trophoblastoma, trophectodermal, and endoderm cells.

\section{RESULTS}

\section{Growth of P19 EC Cells in Semisolid Medium}

The ability to grow in semisolid media in vitro has been highly correlated with tumor formation in vivo (Shin et al., 1975). RA-induced differentiation of EC cells is accompanied by the loss of tumorigenic potential in vivo (Rayner and Graham, 1982) and in vitro (Rodrigues et al., 1985). In the present study we have used P19 EC cells to investigate the temporal relationships among the reduction of growth in soft agar, the cell cycle, and the appearance of other markers of the fully differentiated progeny.

\section{Cell Cycle Dependence}

Initial experiments showed that exponentially growing untreated P19 EC cells rapidly formed colonies in soft agar but that cloning efficiency in medium containing $10 \%$ FCS varied considerably between experiments, with $2-30 \%$ of the cells forming macroscopic colonies within 10 days (not shown). Similar variability (9-85\%) has been observed by others for Nulli-SCCI EC cells (Sherman et al., 1985). Cloning efficiency, however, was significantly increased by increasing the FCS concentration in the soft agar to $20 \%$.Under these conditions, variability between experiments was reduced, with 20 $50 \%$ of control cells forming colonies. In all subsequent experiments, soft agar growth was routinely determined in $20 \% \mathrm{FCS}$.

Previous studies on cell cycle regulation during RAinduced differentiation of PC13 EC cells have shown that using synchronized cells prevents any complications arising from interactions between cells in different cell cycle phases. It does require, however, that intrinsic variations of particular parameters within one cell cycle also be characterized so that their values are known at the time of addition of the inducer. For the soft agar growth of P19 EC cells, the variations during the first cell cycle after synchronization by mitotic selection are shown in Fig. 1. Cells in $G_{1}$ phase form colonies less efficiently than cells in $\mathrm{S}$ phase. Although a number of factors inducing soft agar growth of nontransformed cells have been identified (van Zoelen et al., 1986), the biochemical and genetic basis for the anchorage-independent phenotype of tumor cells remains largely unknown; furthermore, $100 \%$ colony formation of tumor cells is never observed. The reason for the cell cycle variation in soft agar growth shown by P19 EC cells is therefore unclear although the data in Fig. 1 demonstrate that asynchrony is not the reason why a large proportion of exponentially growing cultures fail to form colonies.

\section{Effects of RA: Kinetics of Reduced Colony Formation in Expomentially Growing and Synchromized Cells}

In order to establish when P19 cells lost colony-forming ability after RA addition, exponentially growing cells

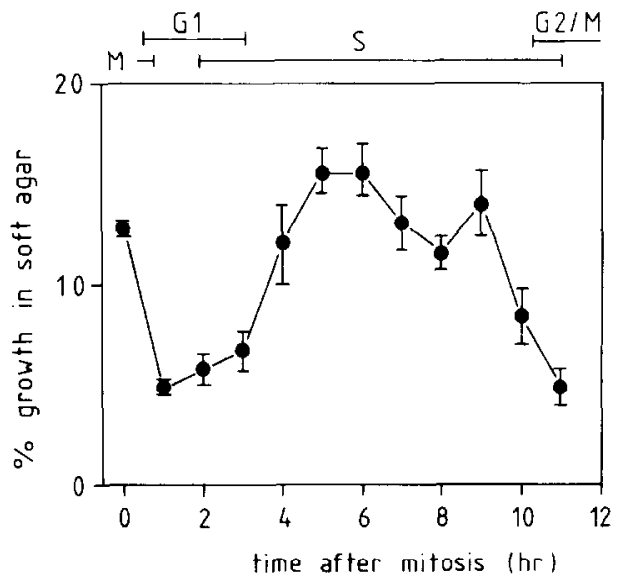

FIG. 1. Soft agar growth during the cell cycle of P19 EC cells. Cells were synchronized by mitotic selection and plated in gelatinized petri dishes at time zero in DF $+7.5 \%$ FCS. At the time indicated, cells were trypsinized, resuspended, and plated in soft agar in $\mathrm{DF}+20 \%$ FCS. Cell cycle phases based on $\left[{ }^{3} \mathrm{H}\right] \mathrm{TdR}$ incorporation and film analysis (not shown) are indicated by horizontal bars. Data given are the means $( \pm$ SEM) of three separate experiments with each point determined in fourfold. 
were treated in monolayer for various lengths of time introduced into soft agar in the absence of RA, and colony formation was scored 10 days later. Figure 2 shows that $10 \mathrm{hr}$ elapsed before anchorage-independent growth decreased and that at least $24 \mathrm{hr}$ of exposure was required before colony formation became insignificant. A similar time course has been observed by others in exponentially growing F9 cells treated with RA (Rodrigues et al., 1985). A lag period also occurred before a reduction in growth rate was observed in exponentially growing PC13 EC cells treated with RA (Mummery et al., 1984). Using synchronized cells to follow the effects of RA on cell cycle progression more precisely, the lag period was shown to consist of two complete cell cycles $(24-26 \mathrm{hr})$ in both PC13 and P19 EC cells (Mummery et al., 1984, 1987). To investigate whether the loss of anchorage-independent growth showed a similar cell cycle-dependent lag period, P19 EC cells were synchronized in mitosis, treated for various periods with RA, and then introduced into soft agar in the absence of RA. The results showed that exposure for one complete cell cycle $(13 \mathrm{hr}$; Mummery et al., 1987) was required before colony formation significantly decreased but that after exposure for two cell cycles, no colonies formed (Fig. 2). A lag period of only one complete cell cycle is therefore observed before $\mathrm{RA}$ reduces growth in soft agar. The data in Fig. 2 are expressed relative to control values since soft agar growth itself is cell cycle dependent (Fig. 1). The apparent decrease following exposure of synchronized cells for $0-2 \mathrm{hr}$ with RA is probably not significant since the

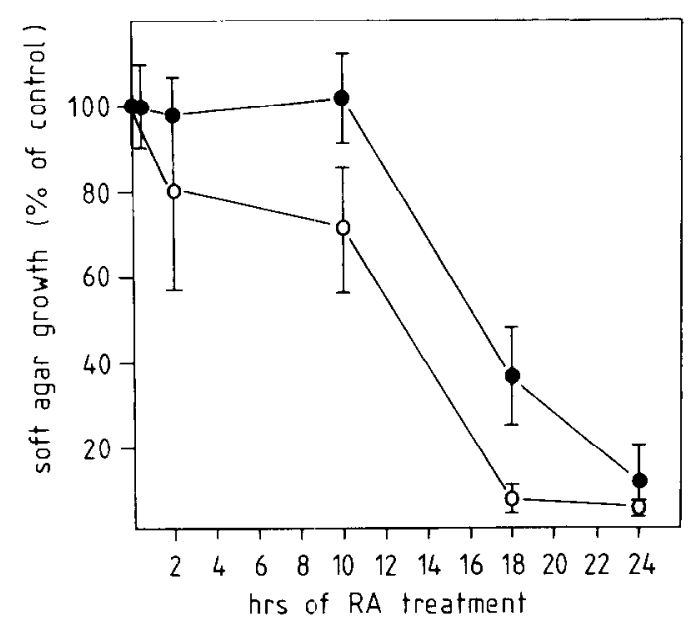

FIG. 2. Effect of retinoic acid on soft agar growth of P19 EC cells. Exponentially growing $(-\infty)$ or synchronized $(O-O)$ P19 FC cells in monolayer at a density of $2 \times 10^{4}$ cells $/ \mathrm{cm}^{2}$ were exposed to RA $\left(10^{-6} M\right)$ in DF medium $+7.5 \%$ FCS; at the time indicated cells were trypsinized, resuspended, and immediately plated in soft agar containing DF medium $+20 \%$ FCS. Colonies were counted 10 days later and expressed as a percentage of control cultures taken at the same time point.

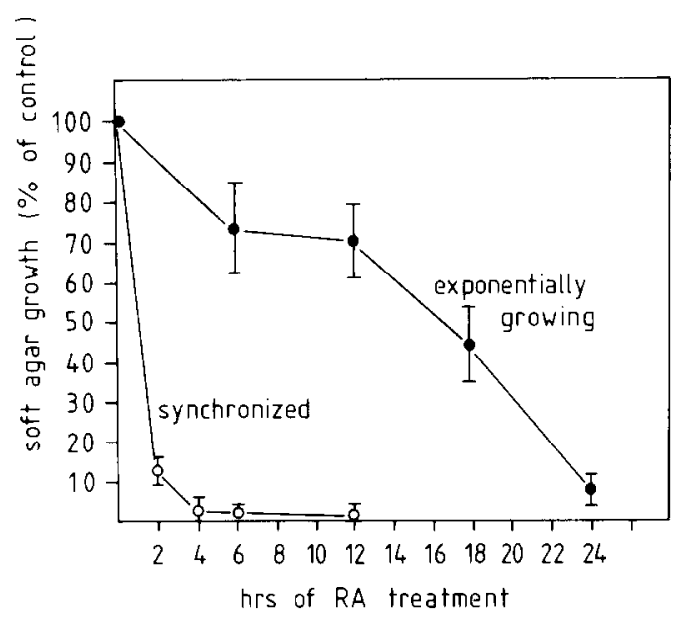

FIG. 3. Commitment of P19 EC cells to differentiation: soft agar growth. Exponentially growing $(-\bullet)$ or synchronized $(O-O)$ EC cells were plated and allowed to attach, and RA $\left(10^{-6} M\right)$ was added at $t=0$. Cell density at $t=0$ was $2 \times 10^{4}$ cells $/ \mathrm{cm}^{2}$ in both cases. RA was then removed at the time indicated and the cultures were incubated further in its absence in DF $+7.5 \%$ FCS before plating in soft agar at $t=80 \mathrm{hr}$ in DF $+20 \%$ FCS. Data are expressed relative to controls taken at the same time point.

intrinsically low capacity for soft agar growth in $\mathrm{G}_{1}$ phase leads to a relatively large error in this data point.

\section{Effects of RA: Commitment and Reversibility in Exponentially Growing and Synchronized cells}

The preceding experiments demonstrated that reduced colony formation in soft agar in P19 EC cells treated in monolayer with $R \Lambda$ occurs after a lag period of at least one cell cycle. The question of when the cells become irreversibly committed to lose the capacity for anchorage-independent growth then arose. P19 EC cells were therefore treated in monolayer for different periods with RA returned to RA-free medium until a fixed time point, and then colony formation in soft agar was tested as above.

In exponentially growing P19 EC cells, short exposures $(6-12 \mathrm{hr})$ to $\mathrm{RA}$ were sufficient to induce a $30 \%$ reduction in the fraction of the cell population still able to grow in soft agar $75 \mathrm{hr}$ later, although at least $24 \mathrm{hr}$ was necessary for all cells to lose their colony-forming ability irreversibly (Fig. 3). In themselves, these short exposures did not affect colony-forming ability when cells were plated in soft agar immediately after RA removal (Fig. 2). By contrast much shorter exposures were sufficient to induce commitment for anchorage-dependent growth in synchronized P19 EC cells (Fig. 3). Addition of RA to mitotic cells for $2 \mathrm{hr}$ or more at the beginning of the first cell cycle induced complete loss of colony-forming potential $75 \mathrm{hr}$ later; cells had divided at least three 
times during this period. The results have several implications. First, the ability of RA to induce anchoragedependent growth may be cell cycle dependent. Second, progression of differentiation appears to require substrate attachment, since synchronized cells exposed to $\mathrm{RA}$ for up to $10 \mathrm{hr}$ and then immediately plated in agar (Fig. 2) still form colonies while those attached to a substrate for a certain period after RA removal lose this capacity entirely even though their exposure to RA may have been much shorter (Fig. 3). Third, reduced soft agar growth is observable in the second cell cycle after induction; it therefore preceded the increase in cell cycle duration induced by RA by one cycle (Mummery et al., 1987; see also Mummery et al., 1984), suggesting that these events are uncoupled and that reduced colony formation is not simply the result of a general decrease in growth rate.

\section{RA-Induced Commitment for Anchorage-Dependent Growth Is Cell Cycle Dependent}

The apparent cell cycle dependence of RA-induced commitment for anchorage-dependent growth suggested by the previous experiments was investigated further by exposing synchronized EC cells in monolayer to pulses of RA during different cell cycle phases and assaying for their capacity to grow in soft agar $75 \mathrm{hr}$ later. The results of these experiments are shown in Fig. 4. In control cultures, synchronized at $t=0$ but not treated with RA, $50 \pm 5 \%$ (mean $\pm \mathrm{SEM} ; n=6$ ) of the cells formed colonies when plated in soft agar $75 \mathrm{hr}$ later. Parallel

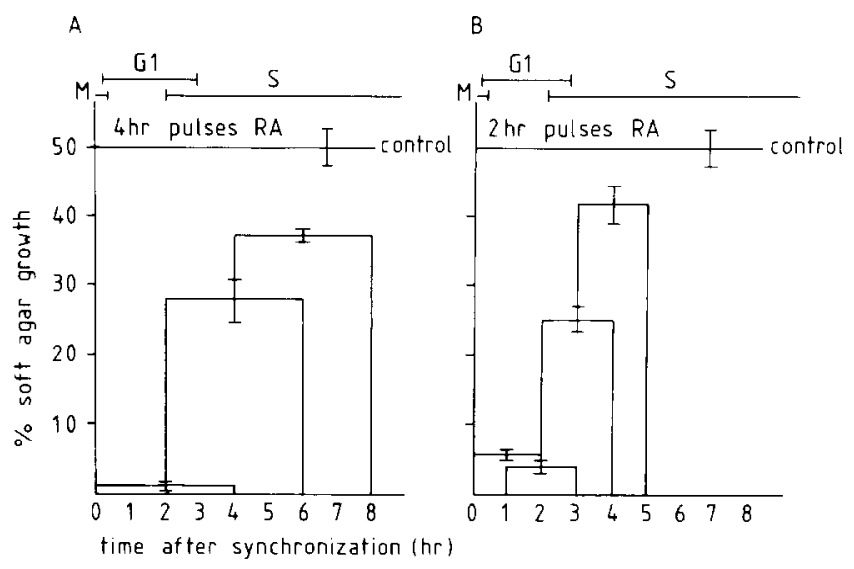

FIG. 4. Effect of pulsed RA treatment on the commitment of synchronized P19 EC cells to differentiation: soft agar growth. Cells were synchronized at $t=0$, and RA $\left(10^{-6} M\right)$ was added for 2 - or 4 -hr pulses at the times indicated. After removal of RA, cultures were incubated further in DF $+7.5 \% \mathrm{FCS}$ before plating in soft agar at $t=75 \mathrm{hr}$ in DF $+20 \%$ FCS. Data shown are the percentages of cells plated which had formed macroscopic colonies after 10 days. Each point shows the mean of four separate dishes ( \pm SEM). Control cultures were synchronized at $t=0$ but were further untreated until $t=75 \mathrm{hr}$ cultures treated with $\mathrm{RA}$ for the first $4 \mathrm{hr}$ after replating $(t=0-4 \mathrm{hr}$ ) but further incubated in RA-free medium had completely lost their ability to form colonies $75 \mathrm{hr}$ later. Their morphology at the time of replating in agar is shown in Fig. 5. By contrast, a similar 4 -hr period of exposure to RA between $t=4$ and $8 \mathrm{hr}$ induced only a small decrease in soft agar growth of cells $75 \mathrm{hr}$ later with almost $40 \%$ of the cells still forming colonies (Fig. 4). Thus the reduction induced by RA exposure immediately after synchronization was not due simply to inadequate removal of RA. Like PC13 EC cells (Mummery et al., 1984), P19 EC cells are synchronized in mitosis primarily as large single cells, form sister pairs when replated at $t=0$, and then proceed through $\mathrm{G}_{1}$ phase. $\left[{ }^{3} \mathrm{H}\right] \mathrm{TdR}$ incorporation shows that the $\mathrm{G}_{1} / \mathrm{S}$-phase transition occurs between 2 and $3 \mathrm{hr}$ after mitosis and most cells are in $\mathrm{S}$ phase at $t=4 \mathrm{hr}$ (data not shown, but indicated schematically in Figs. 1 and 4). Exposure of cells to RA for a 4-hr period including $\mathrm{G}_{1}$ phase clearly had a greater effect than a similar period in $S$ phase. The effect became even more striking when cells were exposed to pulses of $2 \mathrm{hr}$ duration, as shown in Fig. 4B.

In order to eliminate the possibility that the susceptibility of cells to RA immediately after synchronization was not related to cell cycle phases but was an artefact introduced by mitotic shake off, we also exposed cells to RA for 2-hr pulses at the end of the first cell cycle and the beginning of the second cell cycle following synchronization. These results (Table 1) again showed that a 2-hr pulse during the first $\mathrm{G}_{1}$ phase was sufficient to eliminate soft agar growth $75 \mathrm{hr}$ later while a 2 -hr pulse in $\mathrm{S}$ phase had only a marginal effect. More importantly however, the results showed that a 2 -hr pulse from 12 $14 \mathrm{hr}$ (not shown) or 13-15 hr (Table 1), coincident with the second $G_{1}$ phase after synchronization, was again sufficient to eliminate soft agar growth $75 \mathrm{hr}$ later.

\section{Other Differentiation Markers: Plasminogen Activator Production and EGF Binding}

RA has been shown to induce plasminogen activator production and the expression of EGF receptors in a variety of EC cell lines (Strickland and Mahdavi, 1978; Ress et al., 1979; Rodrigues et al., 1985) which are thought to be markers of certain differentiated cell lineages. We have followed the kinetics with which these markers become detectable during RA-induced differentiation of P19 EC cells to establish the temporal relationship with the loss of malignant phenotype. Figure 6 shows that in the continuous presence of $\mathrm{RA}$, the increase in plasminogen activator occurred only after a lag period of at least $16 \mathrm{hr}$ in exponentially growing cells, while $3-5$ :ays elapsed before EGF receptor expression became detectable (Fig. 6). 

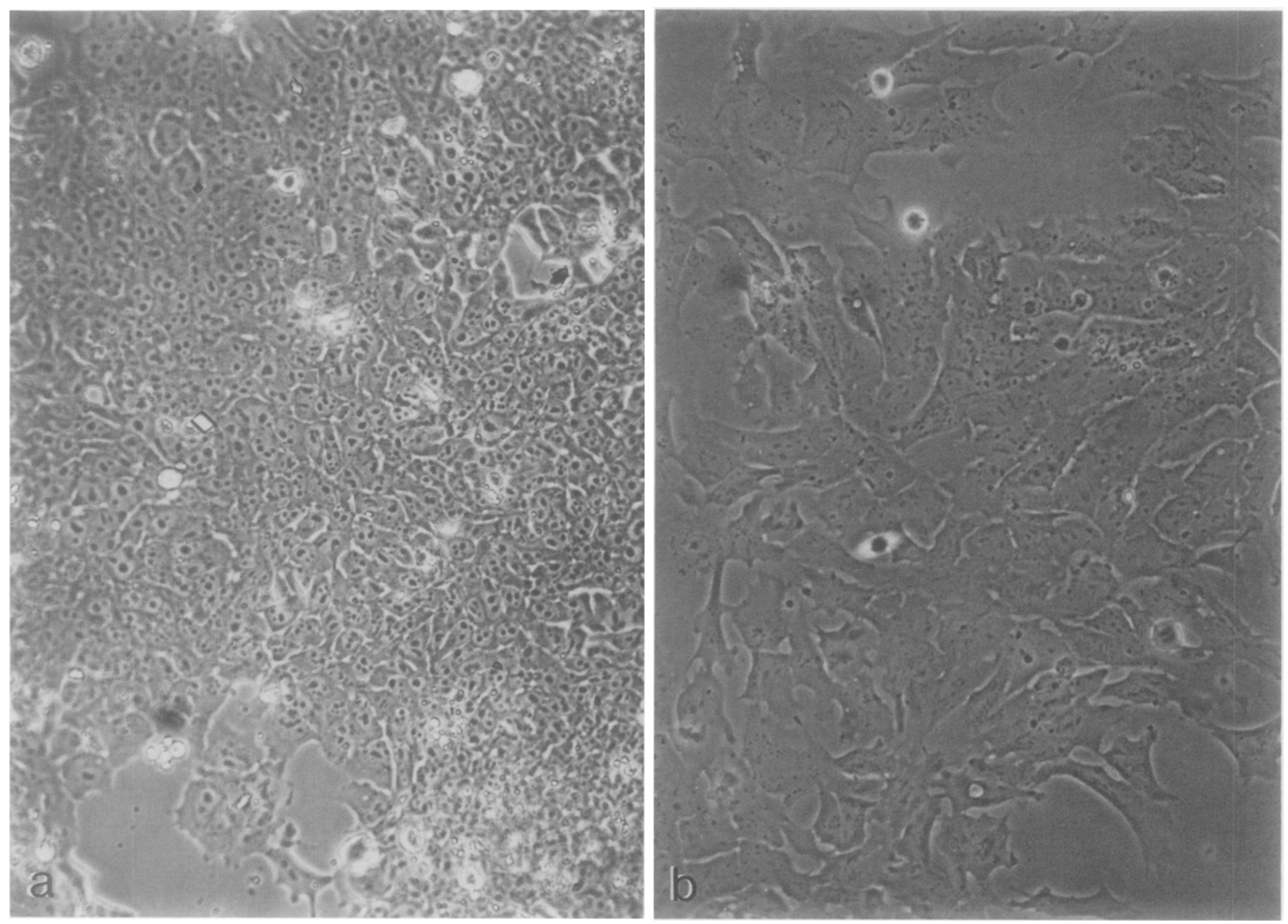

Fig. 5. Effect of pulsed RA treatment on the commitment of synchronized P19 EC cells to differentiation: morphology. Cells were synchronized at $t=0$ and replated, and RA was added for $4 \mathrm{hr}$ as required. Photomicrographs were made at $t=75 \mathrm{hr}$ just prior to plating in soft agar as in Fig. 6. (a) Control. (b) RA exposure from $t=0$ to $t=4 \mathrm{hr}$.

Synchronized cells treated with RA for a period incorporating the $\mathrm{G}_{1}$ phase of the cell cycle were shown to be committed to developing both anchorage dependence for growth and a flattened morphology of cells during the $75 \mathrm{hr}$ following $\mathrm{RA}$ removal. The extent to which these cells had retained EC-specific markers or had acquired those of differentiated cells derived by continuous RA exposure was investigated. Cells were therefore synchronized, treated for various periods with
RA, and then PA production and EGF binding were determined at the time maximum levels were normally reached (see Figs. 5a and 5b); i.e., PA levels were determined in medium conditioned between 50 and $70 \mathrm{hr}$ after initial synchronization and EGF binding was determined on Day 7. Undifferentiated EC cells were not evident in the cultures at the time the experiments were carried out. Figure 7A shows that minimally $24 \mathrm{hr}$ of exposure to RA was necessary to induce PA production. Similarly,

TABLE 1

Effect of Pulsed Treatment on Commitment of Synchronized P19 EC Cells to Differentiation: Comparison of Effects in First and Second Cell Cycle

\begin{tabular}{|c|c|c|c|c|c|}
\hline & Controls & $\begin{array}{c}\mathrm{G}_{1} \\
\text { phase }\end{array}$ & S phase & $\begin{array}{l}\mathrm{S} / \mathrm{G}_{2} \\
\text { phase }\end{array}$ & $\begin{array}{c}\text { Second } G_{1} \\
\text { phase }\end{array}$ \\
\hline RA pulse (time after synchronization, hr) & None & $0-2$ & $5-7$ & $10-12$ & $13-15$ \\
\hline Soft agar growth (\% of control) & 100 & $1.7 \pm 1.1$ & $89.4 \pm 14.4$ & $53.9 \pm 15.5$ & $1.7 \pm 1.7$ \\
\hline
\end{tabular}

Note. RA $\left(10^{-6} \mathrm{M}\right)$ was present for periods of $2 \mathrm{hr}$ as indicated (cells synchronized in mitosis at $t=0 \mathrm{hr}$ ); the cells were then allowed to grow in the absence of RA until introduction into soft agar at $t=75 \mathrm{hr}$. 

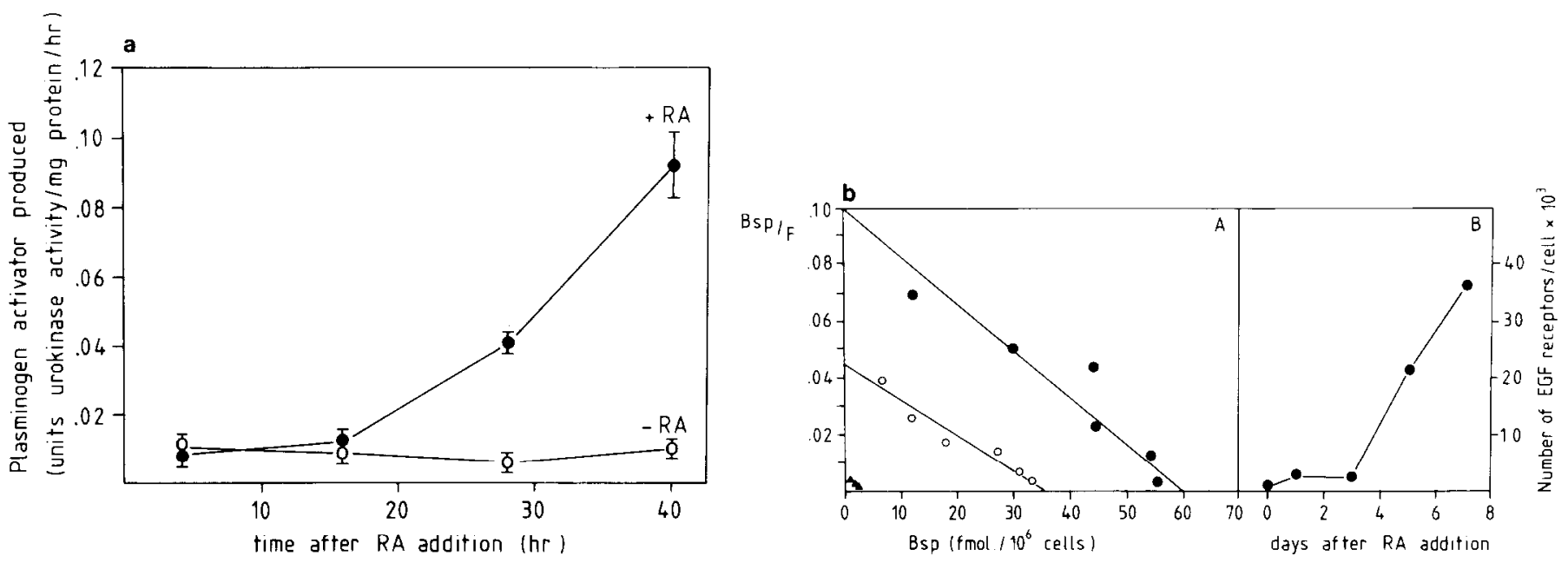

Fic. 6. Effect of RA on differentiation markers in exponentially growing P19 EC cells. (a) Plasminogen activator production. Cells were plated in gelatinized petri dishes and RA $\left(10^{-6} \mathrm{M}\right)$ was added $12 \mathrm{hr}$ later at time zero. Fresh medium $(800 \mu \mathrm{l})$ was conditioned for 8 or $16 \mathrm{hr}$ at various times and levels of plasminogen activator were determined as described under Materials and Methods. Data are expressed relative to human urokinase as standard per milligram of cell protein at the end of the conditioning period. Production rates (mean \pm SEM; $n=3$ ) are indicated in the middle of the conditioning period. (b) EGF binding. Cells were plated as in a, and EGF binding was determined as described under Materials and Methods. (A) Scatchard analysis of binding data $3(\Delta-\Delta), 5(O-O)$, and $7(\bullet-\bullet)$ days after RA addition. (R) number of EGF receptors per cell determined as the intercept of Scatchard curves shown in $A$.

short exposure to $\mathrm{RA}$ in $\mathrm{G}_{1}$ phase did not induce detectablc increases in EGF receptor expression (Fig. 7B). Again, at least $24 \mathrm{hr}$ was required before levels of cxpression comparable to those in cells exposed continuously to RA were found, i.e., more than 40,000 receptors/cell (Mummery et al., 1985, 1986, and Figure 6).

\section{Anti-SSEA-1, TROMA-1, and Laminin Markers}

SSEA-1 determinants are characteristically expressed by EC cells, while laminin, an extracellular matrix protein, and Endo A, a cytoskeletal protein recognized by TROMA-1 antibodies, are expressed by differentiated endodermlike cells. Using indirect immunofluorescence and a monoclonal antibody against SSEA-1 (Solter and Knowles, 1978), we showed that P19 EC cells expressed SSEA-1 determinants as expected (Figs $8 \mathrm{a}$ and $8 \mathrm{~b}$ ), but the majority of synchronized cells exposed to RA for 4 $\mathrm{hr}$ at the beginning of the first cycle no longer expressed SSEA-1 75 hr later (Figs. 8c and 8d). Very few cells with EC morphology were present; these had retained antiSSEA-1 binding. No specific labeling with the anti-laminin antibody was detected although the cytoskeleton of approximately $10 \%$ of the cells was specifically labeled by TROMA-1 (Table 2). Virtually all cells continuously exposed to RA for this period bound anti-laminin antibodies and TROMA-1. Results using indirect immunofluorescence were confirmed in a more sensitive ELISA assay (data not shown). Thus, although morphological changes were induced by pulsed RA exposure, they were not the result of changes in the secretion of laminin or on the intermediate filaments of the cytoskeleton recognized by TROMA-1.

\section{DISCUSSION}

The present study has shown that P19 EC cells respond differentially to RA when they are at different stages of the cell cycle. By using cells synchronized by mitotic
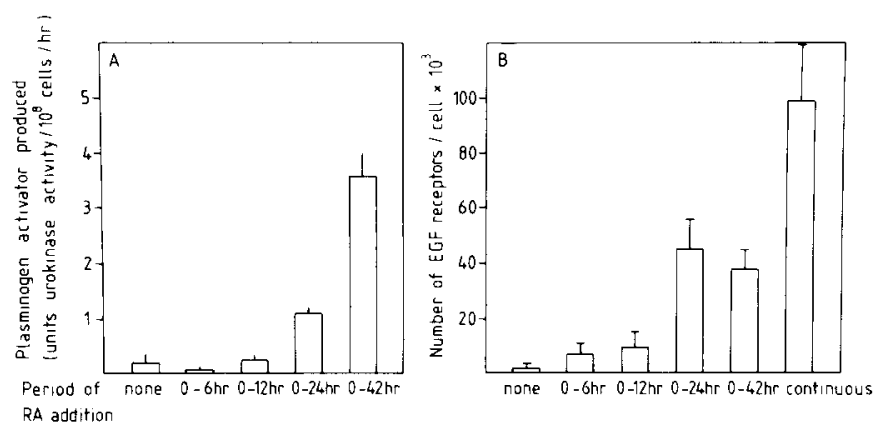

FIG. 7. Commitment to differentiation. (A) Plasminogen activator production induced in synchronized P19 EC cells following pulsed exposure to RA. Cells were synchronized in mitosis and replated in the presence of RA at $t=0$. At $t=6,12,24$, and $42 \mathrm{hr}$, RA was removed by changing the medium. From $t=50 \mathrm{hr}$ to $t=70 \mathrm{hr}, 800 \mu \mathrm{l}$ of medium was conditioned and the amount of plasminogen activator produced in that period was determined, as described under Materials and Methods. (B) EGF receptor expression induced in synchronized P19 EC cells following pulsed exposure to $\mathrm{RA}$ as for PA production in A. EGF binding was determined on Day 7 after initial synchronization, as described under Materials and Methods. The number of EGF receptors per cell was determined from a Scatchard analysis of the binding data, as in Figure $6 \mathrm{~b}$. 

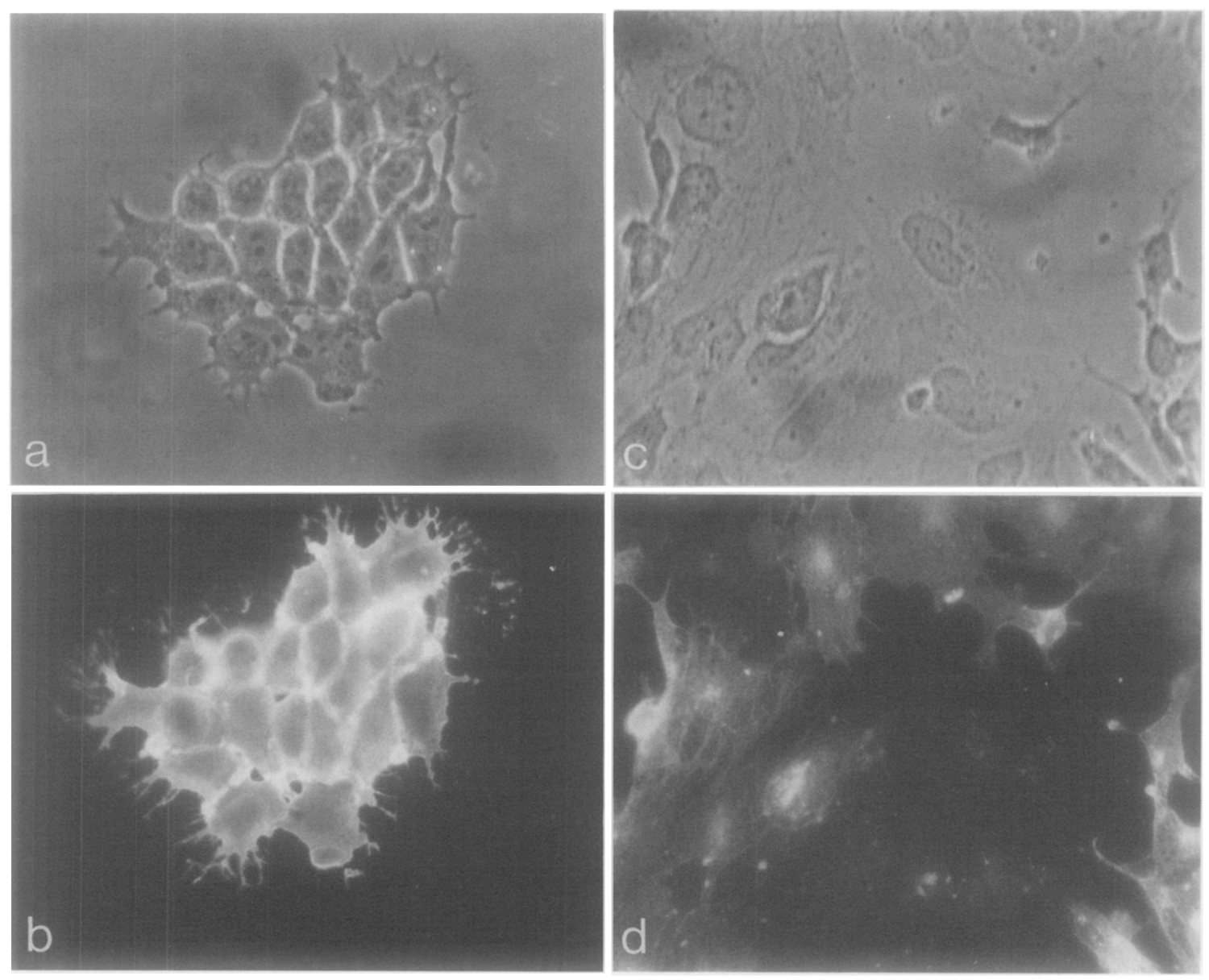

FIG. 8. Effect of pulsed RA treatment on SSEA-1 expression. Cells were synchronized at $t=0$ and replated, and RA was added for 4 hr as required. Expression of SSEA-1 was determined at $t=75 \mathrm{hr}$ by immunofluorescence as described under Materials and Methods. (a, b) without $\mathrm{RA}$; (c, d) with RA for $t=0-4 \mathrm{hr}$. (a, c) phase contrast; (b, d) fluorescence.

shake off and exposing them to pulses of RA at different times thereafter, we have demonstrated that cells in the $\mathrm{G}_{1}$ phase of the cell cycle are exquisitely sensitive to the induction of differentiation as defined by the loss of colony-forming ability in soft agar. The conclusion from the present experiment is similar to that derived by Griep and De Luca (1986) in more indirect experiments using partially synchronized F9 EC cells. In these experiments, $80 \%$ synchrony in early S phase was induced by growing cells at low serum and high thymidine concentrations. Addition of RA for a few hours immediately after release of the $\mathrm{S}$ phase block induced significantly greater numbers of differentiated cells $36 \mathrm{hr}$ later than $\mathrm{RA}$ addition for a similar period $13 \mathrm{hr}$ after release. The effect of using thymidine for cell synchronization in these studies may however have been significant since $17-24 \%$ of colonies contained differentiated cells even without RA treatment. Although this increased to $85 \%$ after early RA treatment, it may have been greater if the degree of synchrony had been as high as that achieved by mitotic shake off. Cell cycle specificity in the inducation of myeloid differentiation by RA has also been observed in HL60 cells and has been correlated with enhanced uptake of the inducer during the sensitive phases (Yen and Albright, 1984).

Loss of anchorage-independent growth is one of the

TABLE 2

EXPRESSION OF SSEA-1 Antigen AND LAMiNin SECRETION by SynChronized P19 EC Cells Exposed to RA DETERMined by INDIRECT IMMUNOFLUORESCENCE

\begin{tabular}{lccc}
$\begin{array}{l}\text { Period of RA } \\
\text { exposure }\end{array}$ & SSEA-1 & Laminin & TROMA-1 \\
\hline None & + & - & - \\
$0-4 \mathrm{hr}$ & - & - & \pm \\
Continuously & - & + & + \\
\hline
\end{tabular}

Note. RA was present as indicated; labeling was determined $75 \mathrm{hr}$ after initial synchronization. 
earliest effects of RA on the EC cell phenotype (JonesVilleneuve et al., 1983; Edwards et al., 1983; Rodrigues et al., 1985); in synchronized P19 cells, this could be clearly shown to occur in the second cycle after induction. Similarly, the flattened morphology typical of differentiated cells was first evident in the second cycle after induction by RA, and, like anchorage dependence, was specifically induced in synchronized cells by $G_{1}$-phase exposure to RA. Cells therefore became anchorage dependent before the cell cycle duration increased and also before $\mathrm{EGF}$ receptor expression and $\mathrm{PA}$ production were detectable.

EGF receptor expression and $\mathrm{PA}$ production appeared to be relatively late markers of differentiation in cells continuously exposed to RA and were only expressed at significant levels in synchronized cells treated for at least $24 \mathrm{hr}$ with RA. This may indicate that the anchoragedependent cells derived by $\mathrm{G}_{1}$-phase exposure to $\mathrm{RA}$ represent intermediate states of differentiation. Alternatively, and in view of previous observations that different doses of RA induce the development of different cell types in P19 cells (Edwards and McBurney, 1983), the length of exposure to RA may play a role in determining which cell types eventually develop. If this interpretation is correct, then the requirement of a long exposure to retinoic acid for the appearance of PA and EGF receptor is a consequence of RA action upon cells committed to differentiate but not yet committed to the particular developmental lineage for which PA and EGF receptors are markers.

$\mathrm{G}_{\mathbf{1}}$-phase exposure was clearly sufficient to commit synchronized cells to anchorage dependence, but comparison of Figs. 3 and 4 suggested that more complex cellular interactions were involved in the commitment of nonsynchronized cells. During a 13 -hr period, it would be expected that all cells in exponentially growing cultures would have been exposed to RA during $G_{1}$ phase and, therefore, that all cells would be committed. Figure 3 showed that this was not the case; after $13 \mathrm{hr}$ of exposure, only a fraction of the population was committed while $24 \mathrm{hr}$ was required for commitment to be complete. Communication via diffusible factors or direct cell contact between cells in different cell cycle phases may inhibit the ability of the $G_{1}$-phase cells to respond to the inducer and become committed to anchorage dependence and might be the reason for this discrepancy. Cell interaction is indeed known to affect P19 differentiation in DMSO, although not in RA (Campione-Piccardo et al., 1985). Alternatively, RA may be metabolized more rapidly in unsynchronized cultures and, therefore, reduced more quickly to ineffective concentrations. Further experimentation is required to distinguish these possibilities.

The reason for the the cell cycle speciticity in the induction of initial events leading to the differentiation of
P19 cells is unclear at present. Changes in gene expression are known to be induced following binding or interaction of RA with intracellular retinoid binding proteins (Linder et al., 1981). Specific RA-binding proteins (RABP) have been detected in various cell types (reviewed by Schroder et al., 1983), and cell cycle-dependent variations in cytoplasmic levels of cellular retinoic acidbinding protein (CRABP) may well be involved in the cell cycle dependence of RA induction. Certain differentiation-defective EC cell lines derived by mutagenesis (McCue et al., 1983) indeed contain little or no CRABP and metabolize retinoic acid poorly (Gubler and Sherman, 1985). On the other hand, in several tumor cell lines, anchorage-independent growth is unaffected by RA, despite the presence of CRABP (Mukherjee et al., 1983). Another possible mechanism may involve the alteration of specific cell surface membrane glycoconjugates (De Luca et al., 1979; Lotan, 1980). Again in certain transformed cell lines, the ability of RA to induce changes in cell surface glycoproteins has been correlated with its ability to affect soft agar growth. In P19 EC cells we have demonstrated that soft agar growth is cell cycle dependent; cells are most sensitive to induction by $\mathrm{RA}$ in the cell cycle phase where soft agar growth is intrinsically low. Cell surface glycoproteins may change in a cell cycle-dependent manner and the ability of RA to affect these changes may be cell cycle dependent. Synchronization of EC cells by mitotic shake off as in the present study has clearly provided a simple means of unraveling some of the complex events of early differentiation, including identification of the stage of differentiation at which pluripotency is lost. As such, this method has significant potential as a system for studying the relationship between growth regulation and differentiation.

We are grateful to Dr. E. J. J. van Zoelen for many stimulating discussions and advice on this manuscript, and Drs. D. Solter and R. Kemler for the $\alpha$-SSEA- 1 and TROMA-1 antibodies, respectively.

\section{REFERENCES}

Campione-Picardo, J., Sun, J.-J., Craig, J., and McBurney, M. (1985). Cell cycle interaction can influence drug-induced differentiation of murine embryonal carcinoma cells. Dev. Biol. 109, 25-31.

De Luca, L. M., Bhat, P. V., Sasak, W. A., and Adamo, S. (1979). Biosynthesis of phosphoryl and glucosyl phosphoryl derivatives of vitamin A in biological membranes. Fed. Proc. 38, 2535-2539.

EDWARDS, M. K. S., HARRIS, J. F., and McBurneY, M. W. (1983). Induced muscle differentiation in an embryonal carcinoma cell line. Mol. Cell. Biol. 3, 2280-2286.

Edwards, M. K. S., and McBurney, M. W. (1983). The concentration of retinoic acid determined the differentiated cell types formed by a teratocarcinoma cell line. Dev. Biol. 98, 187-191.

GrahaM, C. F. (1977), Teratocarcinoma cells and normal mouse embryogenesis. In "Concepts in mammalian Embryogenesis" (M. I. Sherman and C. F. Graham, Eds.), pp. 315-394. MIT Press, Cambridge, MA. 
Griep, M. L., and DeLuCA, H. F. (1986). Studies on the relation of DNA synthesis to retinoic acid-induced differentiation of F9 teratocarcinoma cells. Exp. Cell Res. 164, 223231.

Gubler, M. L., and Sherman, M. I. (1985). Metabolism of retinoids by embryonal carcinoma cells. J. Biol. Chem. 260, 9552-9558.

HoGAN, B. L. M., TAYLOR, A., and ADAMSON, E. (1981). Cell interactions modulate embryonal carcincma cell differentiation into paretal or visceral endoderm. Nature (London) 291, 235.

Jetten, A. M., JetTen, M. E. R., Shapiro, S., and Poon, J. (1979). Characterization of the action of retinoids on mouse fibroblast cell lines. Exp. Cell Res. 119, 289-299.

Jones-Villeneuve, E. M., MCBurney, M. W., Rogers, K. A., and KALNINS, V. I. (1982). Retinoic acid induces embryonal carcinoma cells to differentiate into neurons and glial cells. J. Cell. Biol. 94, 253-262.

Jones-Villeneuve, E. M. V., Rudnicki, M. A., Harris, J. F., and MCBURNEY, M. W. (1983). Retinoic acid-induced neural differentiation of embryonal carcinoma cells. Mol. Cell. Biol. 3, 2271-2279.

Kemler, R., Brulet, B., Schnebelen, M., Gaillard, J., and Jacob, F. (1981). Reactivity of monoclonal antibodies against intermediate filaments during embryonic development. J. Embryol. Exp. Morphol. 64, 45 .

Linder, S., Krondahl, U., SenNerstam, R., and Ringertz, N. R. (1981). Retinoic acid-induced differentiation of F9 embryonal carcinoma cells. Exp. Cell Res. 132, 453-460.

LOTAN, R. (1980). Effects of vitamin A and its analogs (retinoids) on normal and neoplastic cells. Biochim. Biohpys. Acta 605, 33-91.

Lowry, U. H., Rosebrough, N. J., F'ARr, A. L., and Randall, R. J. (1951). Protein measurement with the Folin-Phenol reagent. J. Biol. Chem. 193, 265-275.

MARTIN, G. (1980). Teratocarcinomas and mammalian embryogenesis. Science 209, 768-775.

McBurney, M. W., Jones-Villeneuve, E. M. V., Edwards, M. K. S., and ANDERson, P. J. (1982). Control of muscle and neuronal differentiation in a cultured embryonal carcinoma cell line. Nature (London) 299, 165-167.

MCRuRney, M., and Rogers, B. J. (1982). Isolation of male embryonal carcinoma cells and their chromosome replication patterns. Dev. Biol. 89, 503-508.

MCCue, P. A., Matthae, K. I., Taketo, M., and Sherman, M. I. (1983). Differentiation-defective mutants of mouse embryonal carcinoma cells: Response to hexamethylenebisacetamide and retinoic acid. Dev. Biol. 96, 416-426.

Mukherjee, B. B., Mobry, P. M., Lacroix, A., and Bhat, P. V. (1983). Restoration of anchorage regulation in transformed cells by retinoic acid (RA) is independent of the presence of cytoplasmic RA-binding proteins. Exp. Cell Res. 147, 63-74.

Mummery, C. L., FeiJen, A., van der SaAg, P. T., van den Brink, C. E., and DE LAAT, S. W. (1985). Clonal variants of differentiated P19 embryonal carcinoma cells exhibit epidermal growth factor receptor kinase activity. Dev. Biol. 109, 402-410.

Mummery, C. L., Feijen, A., van den Brink, S., MoolenaAr, W. H., and DE LAAT, S. W. (1986). Establishment of a differentiated mesodermal line from P19 EC cells expressing functional PDGF and EGF-receptors. Exp. Cell Res. 165, 229-242.

Mummery, C. L., van den Brink, C. E., van der SaAG, P. T., and de LAAT, S. W. (1984). The cell cycle, cell death, and cell morphology during retinoic acid-induced differentiation of embryonal carcinoma cells. Dev. Biol. 104, 297-307.

Mummery, C. L., van Rooijen, N. A., van den Brink, C. E., and De LAAT, S. W. (1987). Cell cycle analysis during retinoic acid-induced differentiation of a human embryonal carcinoma-derived cell line. Cell Differ. 20, in press.

OGiso, Y., Kume, A., Nishimune, Y., and Matsushiro, A. (1982). Reversible and irreversible stages in the transition of cell surface marker during the differentiation of pluripotent teratocarcinoma cell induced with retinoic acid. Exp. Cell Res. 137, 365-373.

RAYNER, M. J., and GraHAM, C. F. (1982). Clonal analysis of the changes in growth phenotype during embryonal carcinoma cell differentiation. J. Cell Sci. 58, 331-344.

Rees, A. R., Adamson, E. D., and Graham, C. F. (1979). Epidermal growth factor receptors increase during the differentiation of $\mathrm{em}-$ bryonal carcinoma cells. Nature (London) 281, 309-311.

RoDrigues, M., BalaCki, D., Newrock, K. M., and MukHerJeE, B. B. (1985). Lack of correlation between loss of anchorage-independent growth and levels of transformation-specific P53 protein in retinoic acid treated F9 embryonal carcinoma cells. Exp. Cell Res. 156, 2230 .

Sherman, M. I., Gubler, M. L., Bakai, U., Harper, M. I., Coppola, G., and YUAN, J. (1985). Role of retinoids in differentiation and growth of embryonal carcinoma cells. In "Retinoids, Differentiation and Disease," Ciba Foundation Symposium 113, pp. 42-60. Pitman, New York.

ShERMAN, M. I. (1986). Differentiation of embryonal carcinoma cells: Commitment, reversibility and refractoriness. In "Current Topics in Developmental Biology" (T. S. Okado and H. Kondoh, Eds.), Vol. 20, pp. 345-356. Academic Press, Orlando.

Shin, S. I., Freedman, V. H., Risser, R., and Pollack, R. (1975). Tumorigenicity of virus transformed eclls in nude mice is correlated specifically with anchorage independent growth in vitro. Proc. Natl. Acad. Sci. USA 72, 4435-4439.

SCHRODER, E. W., RAPAPORT, E., and Black, P. H. (1983). Retinoids and cell proliferation. Cancer Surveys 2, 223-240.

Solter, D., and Knowles, B. B. (1978). Monoclonal antibody defining a stage-specific mouse embryonic antigen (SSEA-1). Proc. Nath Acad. Sci. USA 75, 5565-5569.

STRICKLAND, S., and MAHDAVI, V. (1978). The induction of differentiation in teratocarcinoma stem cells by retinoic acid. Cell 15, 393-403.

Strickland, S., SMith, K. K., and NarotTi, K. R. (1980). Hormonal induction of differentiation in teratocarcinoma stem cells: Generation of panetal endoderm by retinoic acid and dibutyryl cAMP. Cell 21, $347-355$.

Todaro, G. J., De Larco, J. E., FriJling, C., Johnson, P. A., and Sporn, M. B. (1981). Transforming growth factors (TGF's): Properties and possible mechanisms of action. J. Supramol. Struct. Cell. Biochem. $15,287-301$.

Yen, A., and Albright, K. L. (1984). Evidence for cell cycle phase specific initiation of a program of HL-60 cell myeloid differentiation mediated by inducer uptake. Cancer Res. 44, 2511-2515.

van ZoElen, E. J. J., VAN OOSTWAard, T. M. J., and DE LAat, S. W. (1986). Transforming growth factor $\beta$ and retinoic acid modulate phenotypic transformation of normal rat kidney cells induced by epidermal growth factor and platelet-derived growth factor. J. Biol. Chem. 261, 5003-5009. 